\title{
BOLETOS SENCILLOS Y PASAJES REDONDOS. INDÍGENAS Y MESTIZOS AMERICANOS QUE VISITARON ESPAÑA
}

\author{
POR
}

JOSÉ LUIS DE ROJAS

Universidad Complutense de Madrid

Partiendo del estudio pionero de Esteban Mira (2001), se rastrean en diversos documentos y crónicas los viajes que indígenas americanos realizaron a España, desde poco tiempo después de la conquista, centrándose en los que lo hicieron voluntariamente o por lo que podriamos llamar «razones de estado». A partir de estas noticias se plantea la necesidad de analizar en profundidad estos viajes, sus motivos y avatares y rastrear la posible constitución de redes personales que abarcaran ambas orillas del océano.

PALABRAS Clave: Indigenas americanos, viajes a España, redes personales.

Hace ya algunos años que Esteban Mira ${ }^{1}$ publicó un libro, que hasta el momento es único en su género, sobre indios y mestizos americanos en la España del siglo XVI. Su objetivo fue, principalmente, estudiar a quienes viajaban forzados, muchas veces en condición de esclavos, y eran abandonados en la Península. Sus datos recogen varios miles de individuos, pero supone que debieron ser muchos más. Entre ellos aparecen de vez en cuando personajes como los descendientes de Moctezuma, quienes disfrutaron de unas condiciones de viaje muy diferentes.

A la lectura del libro hemos sumado el interés que desde hace tiempo hemos mantenido sobre la familia de Moctezuma $^{2}$, y alguna lectura esporádica como Lohmann ${ }^{3}$, para ir concretando un interés por aquellos indígenas y mes-

1 Mira, 2000.

2 Rojas, 1994: 117-134; 25 (México, 2001): 379-382 (en prensa).

3 Lohmann, XIX (Madrid, 1948-48): 347-458; XXV (Madrid, 1960-61): 450-477. 
tizos que viajaron a la Península Ibérica por voluntad propia. Algunos se quedaron en ella, otros regresaron a sus lugares de origen, y algunos más cruzaron el Atlántico en varias ocasiones.

El tema tiene la importancia suficiente como para merecer un estudio detallado en el que se profundice sobre quiénes eran los que viajaban, en qué circunstancias lo hacían, sobre todo atendiendo a la financiación de los viajes y las estancias, y qué redes permitían los viajes. Esto no solamente se refiere a los contactos que los viajeros tuvieran en la Península Ibérica o que pudieran formar gracias a sus relaciones en sus lugares de origen, sino también a la forma de organizarse la vida americana, sobre todo en el caso de los caciques que se ausentaban por tiempos largos, pues es necesario estudiar cómo continuaron relacionándose con sus posesiones y cómo gestionaron el control de las mismas. También es importante estudiar las compañías que frecuentaban, a uno y otro lado del Atlántico y durante la travesía y es por eso que hemos decidido incluir a los mestizos, pues la mayoría de ellos procedía de matrimonios legítimos y en sus redes familiares se encontraban tanto españoles como indígenas. Tras la anécdota de los viajes se encuentra la realidad de las relaciones personales en América y España, y la manera en que los indígenas incorporaron a su vida la lejana corte.

Para ilustrar la importancia del tema y la necesidad de abordar más profundamente su estudio nos proponemos ahora presentar una muestra de los datos encontrados, con la diversidad de motivos que les hacía emprender tan largo viaje, y plantear algunas preguntas relacionadas con esa actividad, para relanzar el llamamiento a nuevas investigaciones con el que cerró su libro Mira ${ }^{4}$.

Una cuestión que conviene aclarar es que, como hemos mencionado, entre los viajeros hay muchos mestizos, cuya significación procede de su ascendencia indígena, sobre todo los descendientes de Huayna Capac y de Moctezuma. Y que sus familias están compuestas de indios «puros», de españoles y de mestizos en diversos porcentajes de mezcla. Aquí los consideraremos en conjunto, pues nos interesan sobre todo las relaciones entre las personas.

Nos encontramos con varias categorías de individuos que viajan a España. Y lo hacen con motivos distintos, e intenciones dispares. Algunos se proponen solamente realizar una visita. Otros van «a resolver asuntos» y otros más llevan intención de quedarse, a veces porque no les queda más remedio, pues en los primeros tiempos, el miedo a que los descendientes de los señores prehispánicos pudiera acaudillar alguna revuelta hizo que se tratara de enviarlos a España:

Y para que mejor de aquella provincia de Mechoacan vuestra majestad sea servido y los indios descubran las minas de plata, que tienen muchas, e no osan hazerlo

\footnotetext{
4 Mira, 2001: 238.
} 
por temor del caçonçi, que es el señor de aquella provinçia, ay neçessidad que vuestra majestad nos enbíe a mandar por su letra le enbiemos al dicho caçonçi y a otros dos hermanos suyos y prinçipales dellos y a otros señores desta Nueva España porque sacados de aquj, la tierra estará más segura y los de acá descubrirán las mjnas sin temor sabiendo que éstos se han llevado allá y verán a vuestra majestad y su grandeza y se podrá desta tierra sacar mucho servjcio ${ }^{5}$.

La marcha a España de varios hijos de Moctezuma, junto a otros principales mexicanos y los viajes de algunos señores tlaxcaltecas pueden estar relacionados con esta opinión. El asunto se prolongó al Perú, pues como veremos, a comienzos del siglo XVII visita España D. Melchor Carlos Inca, y años después, el virrey Príncipe de Esquilache no ve con buenos ojos la presencia de la nieta de Sayri Tupac en el Perú y fuerza su viaje a España.

Pero los resultados no siempre fueron los esperados, o simplemente, hubo opiniones para todos los gustos:

Otrosí haré relación a su majestad de cómo los naturales que desta Nueva España a Castilla se han llevado y han vuelto, han hecho y hacen mucho daño a la tierra emponiendo a los otros indios a que no sirvan y en otras muchas maldades y traiciones dignas de castigo que son notorias por qué le suplicaré a su majestad mande que los tales que una vez en Castilla fueren, no los vuelvan ni puedan traer a esta Nueva España $^{6}$

Y ese conocimiento tenía una doble cara. En la cita anterior es pernicioso, $\mathrm{y}$ en la que sigue resulta providencial para los españoles:

... pocos días ha que un indio o dos me dijeron [a un franciscano] hablándoles yo desto o de su desvergüenza e que si pensaban hacer alguna bellaquería, el cual me dijo: padre no tengáis recelo deso, pero yo os quiero decir lo que pasa: muchos días ha que en algunas juntas que los principales hemos hecho secretas lo hemos platicado e platicamos y los días pasados pocos días ha que nos juntamos muchos e todas las más cabezas de la tierra e posimos pláticas sobresta razón para que efetuásemos pues ya teníamos alcanzado toda la manera de los españoles, de su pelear e fuerzas e del arte de los caballos e de todo lo demás que inorábamos y no sabíamos e pues víamos tan a la clara que no teníamos una merienda en todos ellos, que no lo dejásemos, ni lo difiriésemos más porque era gran yerro y estando en esto todos dijo uno, que cosa tan grande no se había de comenzar sin certeridad e seguridad de todas partes y que era verdad que de los españoles que estaban en la tierra buena cuenta darían, e que todo lo que dellos se había de alcanzar estaba alcanzado e probado pero que Despaña ni de las cosas de allá no estaban bien ciertos ni sabían las cosas de allá, que satisfechos de esto verían lo que mejor conviniese e como mejor se pusiese en obra; para esto acordaron de llamar a la junta un principal que había venido Despaña en los navíos pasados el cual de acuerdo de todos parescía haber sido en-

5 Albornoz, 1994 [1525]: 40.

6 Instrucciones, 1531: 102. 
viado a ver las cosas Despaña, el cual venido a otra junta e propuesto el razonamiento dicho, le pidieron que por istenso les contase las cosas Despaña e de vuestra majestad el cual había respondido e dijo que pues también tenían calados los españoles de acá, que sobre ellos no había qué decir pues él vía que en todo decían verdad; que cuanto a los Despaña, quél con toda diligencia lo había mirado inquirido e sabido como convenía e que vuestra majestad era hombre como los otros e que tenía gran poder e que se halló en Málaga cuando se hacía la armada para Argel e que vido tanta multitud de navíos e gente que se espantó por manera que allí se juntaron más de ochocientas velas que se cobría la mar e que había gran poder de gente en España e que si acá viniese aquel poder que era muy grande e que ansí en aquella junta se difirió que por el presente se dejase, y esta fue la certeridad quel fraile tenía ${ }^{7}$.

¿Un turista o un espía declarado? La idea es muy bonita y da muestra del alcance del tema que planteamos, con repercusiones a ambos lados del Océano.

\section{LA NUEVA ESPAÑA}

Tenemos noticias de viajes de indios de la Nueva España desde muy temprano. Aparecen citados generalmente nobles y señores, pero no debemos descartar que fueran acompañados por algún tipo de séquito, ya sean servidores, amigos o ambas cosas, como ocurrió en los primeros años 1520 con D. Martín de Moctezuma, a cuya familia dedicaremos un apartado completo. Las noticias suelen ser parciales. A veces contamos solamente con la petición de licencia para viajar, como es el caso de D. Hernando Pimentel, señor de Tetzcoco, quien pidió permiso a Carlos V en 1554 «para ir a visitarlo» ${ }^{8}$. Otras veces tenemos algunos datos más, como las penurias que pasaban para conseguir volver. Claro es que hay que acogerlas con las debidas reservas, pues las peticiones de dinero alegando pobreza estaban muy extendidas, incluso entre individuos tenidos por ricos:

C. real magestad $\backslash \backslash \backslash$ Lorenço de Alameda e Martín de Aguilar, yndios prinçipales e naturales de la çibdad de Mexico que es en los vuestros rreynos de la Nueva España, besamos las rreales manos de vuestra magestad $\mathrm{E}$ como sus humilldes vasallos de aquellas partes, dezimos que nosotros venjmos astos rreynos dEspaña a negoçios e de algunos nos hemos despachado. E agora para nuestro viaje e tornada a nuestro natural e como hombres estranjeros e de fuera destos rreynos, no hemos hallado fabor nj quien nos ayude para camino. $\backslash$ Ocurrimos a vuestra magestad como a nuestro señor natural e de quien hemos de rresjbir merçed para el dicho nuestro viaje e pasaje e liçençia para aquellas partes, como a naturales dellas. $\backslash \backslash$ Pedimos e suplica-

7 López, 1545: 166-167.

8 Horcasitas, 6 (México, 1978): 153. 
mos humillmente a vuestra magestad sea servido de mandar sernos faboresçidos, ansí para nuestro sustento en estos rreynos como para el pasaje a nuestro natural, que en ello rreçibiremos merçed ${ }^{9}$.

Tenemos un caso en el que afirma que un indígena fue a estudiar. Se trata de Pedro Juan Antonio, quien en 1568 llegó a la Universidad de Salamanca para especializarse en derecho y que en 1574 publicó una gramática latina en Barcelona ${ }^{10}$. Hasta el momento no hemos conseguido localizar el libro.

Como veremos, nuestros datos son fundamentalmente de los siglos XVI y XVII, pero también se produjeron visitas en el XVIII, como el caso siguiente:

Acaso el más ingenioso patrón indio de una escuela primaria fue Juan de San Pedro Andrade y Bejarano, el cacique ópata de San Juan Tecomatán (¿Sonora?). En 1799 zarpó rumbo a España para presentar su petición de «una escuela general pública de enseñanza religiosa y civil» ante el Consejo de Indias. Predeciblemente el Consejo le ordenó volver a casa y efectuar su petición ante el virrey. Para suavizar este rechazo el Consejo afirmó que Juan de San Pedro estaba, él mismo, bien calificado para ser maestro de primeras letras y debía ser provisto de lo necesario para su propio sustento. Pero no fue tan fácil quitarse de encima al cacique. Permaneció en Sevilla durante casi dos años y porfió en su petición relativa a la escuela. Para agosto de 1800 consiguió un pequeño estipendio del Consejo para sus estudios y una orden para que se fundara una escuela en su pueblo «si fuera posible» ${ }^{11}$.

\section{Los descendientes de Moctezuma}

Los primeros de quienes tenemos noticias de que viajaron $-\mathrm{y}$ lo hicieron en varias oportunidades cada uno - fueron los hijos de Moctezuma:

... yo d. Martin Neçahualteculchi soi hijo de Montezuma, el qual es notorio que obedecio a los mandamientos de V.M. i se dio por su vasallo i le entrego esta Cibdad e tierras como señor que era de todo ello, e yo he ido dos vezes a besar las manos de V.M. e pedirle $\operatorname{mrds}^{12}$.

Dos veces en diez años, es decir, cuatro travesías. Tezozomoc ${ }^{13}$ nos da más noticias de este señor, afirmando que se casó en España con una española y que murió envenenado a su vuelta a México porque los mexicanos «le tuvieron envidia». Lo que sí sabemos es que no viajó solo. D. Juan Coadhuichil,

9 Petición de licencia de embarque para la Nueva España de dos indígenas que se encuentran en España, 1568, AGI Indiferente General, 2051. En Company, 1994: 160.

10 Aguilar, 33 (México, 2002): 155.

11 Taylor, 1999: 500.

12 Petición a S.M. de los Principales de México, México, 18 de junio de 1532. Real Academia de la Historia, Madrid, Colección Muñoz, 61: f. 175r-178v: f. 175r.

13 Tezozomoc, 1975: 163. 
nieto de Ahuitzotl, dice que fue a besar las manos de S.M. cuando «el Marqués fue a España». Otras fuentes también nos dan noticia del viaje. Hay un cruce de cartas entre la Audiencia y la Corona, en la que aparecen varias veces estos señores. En 1531 la Audiencia de México escribe que había dado maíz y trigo a un hijo de Moctezuma «que fue a besar las manos de Vuestra Majestad a esos Reynos ${ }^{14}$. La Emperatriz responde al año siguiente:

... parece ser que será bien que al dicho fijo de Moteçuma le embieys aca con algund negocio o como procurador desa cibdad o por otra vía que a vosotros paresciere, de manera que venga proveydo de lo que ovieren menester syn que se le de a entender que de aca se os escrive, antes certificándole que le conviene venir para que su magestad le haga merced... 15

La Audiencia parece que había tomado ya alguna determinación antes de llegar esa carta, como consta en la respuesta:

Cuando recibimos la carta de vuestra majestad ya teníamos proveído cómo el hijo de Muteczuma e un sobrino suyo, e un hijo de un gobernador que fué desta cibdad fuesen a besar los reales pies e manos de vuestra majestad y en ello se tuvo la forma que vuestra majestad manda, e fueron con el eleto e con ésta enviamos en lo que vuestra majestad les podrá hacer merced que acá pidieron por petición en el Audiencia ${ }^{16}$.

En otra carta anterior ${ }^{17}$, la Audiencia afirma que un hijo de un sobrino de Montezuma y un hijo de un «gobernador que fue desta cibdad» habían determinado ir a suplicar mercedes a Su Majestad, y que ya habían ido otra vez.

Nombres aparecen en una carta de fray Juan de Zumárraga ${ }^{18}$ : D. Martín, D. Juan y D. Pedro. Del primero ya hemos tratado, y ahora lo haremos del último. D. Pedro Moctezuma quedó a la muerte de su hermano D. Martín como único descendiente varón de Moctezuma y jugó un papel de cierta relevancia en el siglo XVI, que debe ser tratado con mayor atención ${ }^{19}$. En una de sus visitas a España consiguió una merced de 600 pesos de oro de minas de renta anual y en 1569 pedía una de 3.000, que acabó consiguiendo ${ }^{20}$. En su testamento afirma que había ido a Madrid a ver al rey «en el año 40» y que recibió una merced de 1.000 «pesos de tipuzque», que equivalen aproximadamente a

14 Audiencia de México, 1531: 91.

15 Emperatriz, 1532: 118.

16 Audiencia de México, 1532b: 218.

17 Audiencia de México, 1532a: 188-189.

18 Zumárraga, 1533: 34.

19 Rojas, 2001.

20 Carta a S.M. de D. Pedro Moctezuma, México 31 de marzo de 1569, AGI, Sevilla, Patronato, 245, ramo 4: ff. $1 \mathrm{r}-2 \mathrm{v}$. 
los 600 pesos de oro de minas, por lo que debe tratarse de la misma merced ${ }^{21}$. En otra carta de la Audiencia de México $^{22}$ se menciona la estancia de D. Pedro y D. Gabriel «en esa corte». Algunas noticias de las actividades de D. Pedro en España nos son proporcionadas por Mira ${ }^{23}$ :

Encontramos casos de indios bien situados socialmente que decidieron conocer «estos reinos». Ese fue el caso de don Gabriel y de don Pedro (este útimo, hijo del Rey del Imperio Azteca, Moctezuma), que llegaron acompañados por dos indios de servicio y tutelados por Francisco de Santillana «a ver las cosas de España». ${ }^{117}$ ya el 24 de julio de 1533 se le concedió al hijo de Moctezuma el cargo de contino de la Casa Real para que de esta forma se pudiese mantener. ${ }^{118}$ El 22 de noviembre de 1540 solicitaron pasaje para volverse a Nueva España ${ }^{119}$, pero al menos don Pedro continuaba reclamando permiso para retornar a México ${ }^{120}$ dos años después ${ }^{24}$.

Se trata del segundo viaje de D. Pedro Tlacahuepan, pues en 1530 había regresado a la Nueva España en buena compañía:

En este mismo [año (1530)] regresó don Hernando Cortés, marqués del Valle. Había estado en España durante 3 años. Con él venían varios príncipes nativos y con quien más andaba era con la persona de don Pedro de Moctezuma Tlacahuepan Yohualcahuacatzin, hijo del que fue el poderoso Señor Moteuhctzomatzin. Otro de ellos era don Francisco de Alvarado Matlaccohuatzin, quien era hijito de Tezozomoctzin Aculnahuacatl, quien fue hermano carnal del dicho Moteuhczomatzin $^{25}$.

Uno de los hijos de don Pedro, Diego Luis fue obligado por la autoridades a pasar a España en $1567^{26}$. Casó con una noble perteneciente a la casa del Duque de Albuquerque, heredó el mayorazgo de don Pedro por muerte de su hermano mayor y murió asimismo en Valladolid el 31 de mayo de 1606. Había fijado su residencia en Guadix, donde nació su hijo primogénito, Pedro Tesifón en 1581. Éste fue caballero de la Orden de Santiago. En 1627, recibió el título de vizconde de Ilucan en febrero y en septiembre del mismo año, el de Conde

21 Los pesos de oro de minas eran de 450 maravedises, por lo que la merced sumaba 270.000. Los pesos de oro de tipuzque son de 272 maravedises, alcanzando un total de 272.000 .

22 Audiencia de México, 1541: 28.

23 Mira, 2001: 85.

24 Las referencias de la cita de Mira, son: 117. Real Cédula a los oficiales de la Casa de Contratación, Ocaña 27 de diciembre de 1542. AGI Indiferente General 1963, 1. 8, ff. 96v-97r. 118. Heredia Herrero, Antonia: Catálogo de consultas del Consejo de Indias. Dirección General de Archivos y Bibliotecas, Madrid 1972, t. I: 36. 119. Real Cédula a los oficiales de la Casa de Contratación. Ocaña 27 de diciembre de 1542. AGI Indiferente General 1963, L. 8, ff. $96 \mathrm{v}-97 \mathrm{r}$.

25 Chimalpahin, 1965: 251.

26 Álvarez, 1994: 105. 
de Moctezuma de Tultengo ${ }^{27}$. Una nieta suya estuvo casada con don José Sarmiento de Valladares, quien fue Virrey de la Nueva España a fines del siglo XVII, ostentando el título de su esposa. En el siglo XIX el título fue elevado al rango de ducado.

Un episodio de los primeros tiempos de D. Diego Luis de Moctezuma en España nos descubre otros viajeros y la forma en que se relacionaban:

Forced to find a means of supporting himself in Seville, Diego Luis hoped to buy and sell decks of playing cards on a grand scale. To do this, in 1573 he had borrowed hundreds of thousands of maravedis to purchase 3,500 dozen packs of cards at 640 maravedis per dozen. He managed to get his cousin Juan de Andrade, also in Seville, to serve as guarantor of the loan. Unfortunately for the cousins, they not only owed the principal but also 600,000 maravedis to the king and Castle's treasurer general, Bernabé Álvarez de Loaysa, the crown representative in Sevilla. The sum was for 1,111 dozen packs of playing cards that did nor bear revenue stamps containing the royal seal ${ }^{28}$.

Dos años en la cárcel les supuso a los primos el fallido negocio. Pero lo que en este momento nos interesa es ver las relaciones que mantenían los parientes o vecinos que se encontraban en España. Juan de Andrade era el hijo mayor de Isabel de Moctezuma y compartía con Diego Luis la condición de nieto del emperador azteca. Uno era mestizo y el otro completamente indígena, pero eso no fue obstáculo para que trataran negocios juntos en España. La presencia de Juan de Andrade debía obedecer a los numerosos pleitos que siguieron a la muerte de su madre, Isabel de Moctezuma, entre su hijo mayor, único nacido en el matrimonio con Pedro Gallego de Andrade, y el viudo Juan Cano de Saavedra y sus hijos ${ }^{29}$. Poco más sabemos de Juan de Andrade, quien murió antes de que se sentenciaran los pletios. Sus hijos recibieron mercedes en forma de rentas ${ }^{30}$, hicieron buenas bodas y dieron origen a los condes de Miravalle-Moctezuma.

Los hijos de Juan Cano tuvieron otra fortuna, tanto en la época como entre los estudiosos. Tuvieron negocios en la península, vinculados a Sevilla y Cáceres $^{31}$, y una rama de la familia, la descendiente de Juan Cano Moctezuma permaneció en España, alcanzando diversos títulos y construyendo un palacio en Cáceres: el de los Toledo-Moctezuma. D. Diego Luis vino a España en

27 Álvarez, 1994: 105-106.

28 Chipman, 2005: 94.

29 Rojas, 1994

30 Real Cédula señalando mercedes a los sucesores de doña Isabel Moctezuma, en sus segundo y tercer matrimonio con Pedro Gallego y Juan Cano, 1590, Real Academia de la Historia, Madrid, col. Muñoz, 15: 188r-191v, f. 189r-190r.

31 Pelegrí, 2004. 
$1565^{32}$ y aquí casó con doña Elvira de Toledo. La entrada del Diccionario Porrúa ${ }^{33}$ resume muy bien la evolución de la familia:

Hicieron la fundación del mayorazgo de Moctezuma en Granada 1577, teniendo por hijo a D. Juan de Toledo Moctezuma, casado con Dña. Mariana de Carvajal, siendo estos padres de D. Juan de Moctezuma Carvajal y Toledo, caballero de Alcántara en 1625, marido éste de Dña. Isabel Antonia María de Pizarro, y padres de Dña. Mariana de Moctezuma Carvajal y Toledo, casada con D. Álvaro de Vivero, hijo del conde de Fuensaldaña y teniendo por hija a Dña. María de Vivero Moctezuma, quien casó con D. Juan de Carvajal y Sande, Conde de Enjarada, teniendo un hijo, llamdo D. Bernardino de Carvajal y Vivero, Conde de Enjarada, casándose con doña Isabel Alencastre y Noroña, hija y heredera del Duque de Abrantes, por falta de varón. De este linaje descienden los duques de Abrantes, que lo son también de Linares.

Contamos con dos linajes de Moctezumas con título nobiliario que quedaron en España, disfrutando de rentas en la Nueva España, lo que necesariamente generó relaciones y vínculos para las gestiones, cobros y envíos y probablemente redes de recomendación y atención para los viajeros, tanto los que iban de España para América, como al contrario. Y estas relaciones son lo que falta por investigar.

\section{Los tlaxcaltecas}

Los tlaxcaltecas, fieles aliados de Hernán Cortés en la conquista, tuvieron una gran movilidad. Un contingente de ellos acompañó a Pedro de Alvarado en la conquista de Guatemala, y algunos pasaron con él al Perú más tarde ${ }^{34}$. Fueron protagonistas de la colonización del norte de México ${ }^{35}$. Y no podían faltar las visitas a España. Uno de los hijos de Maxixcatzin, señor de una de las parcialidades de Tlaxcala, de nombre D. Lorenzo Maxiscatzin viajó a España para dar personalmente la obediencia al Emperador D. Carlos, y murió en la península ${ }^{36}$. Gibson ${ }^{37}$ afirma que el viaje fue en 1527 y que le acompañaron Valeriano de Castañeda, Julián Quauhpitzintli, Juan Citalihuitzin y Antonio Huatlatotzin. Era la misma expedición en la que viajaron con Cortés Pedro Tlacahuepan y Francisco de Alvarado Matlaccohuatzin, junto a otros nobles. El regreso se produjo en 1530.

\footnotetext{
32 Bautista, 2001: 306, 307.

33 Diccionario Porrúa, 1976, I: 352.

34 Lockhart, 1982. Muñoz Camargo, 1984: 280.

35 Martínez, 170 (México, 1993): 195-250.

36 Muñoz Camargo, 1984: 166.

37 Gibson, 1967: 164.
} 
Item., si saben que D. Diego y D. Martín, indios de Tascala ya difuntos, y Sebastián, natural de la dicha Tascala, fueron con el Lic. Salmerón a España, solo por ver y conocer a S. M.; los cuales el visorey cuando pasó a estas partes los volvió consigo, y eran personas honradas y buenos cristianos, y amigos de españoles: digan lo que saben $\&$ c. ${ }^{38}$

Buena compañía para ir y mejor para volver. Sería interesante conocer las relaciones durante los viajes y desde luego, las actividades en España. El motivo del viaje es también interesante: ¿estamos ante turistas del siglo XVI? Las fechas son 1534 para la ida y 1535 para el regreso ${ }^{39}$. Don Diego, de apellido Maxixcatzin, obtuvo del emperador cédulas concediendo un escudo de armas y la promesa de que nunca saldría Tlaxcala del control de la corona.

Otro cronista de Tlaxcala, don Juan Buenaventura Zapata nos ha dejado el testimonio de varias visitas: en 1540 fueron a Castilla Leonardo Cortés y Felipe Ortiz, en lo que al margen se califica de «tercera ida a España de los tlaxcaltecas ${ }^{40}$, en 1569 se dice que «vinieron los que se fueron a Castilla» ${ }^{41}$ pero no queda claro si se trata de los que se marcharon en 1540 o de otro viaje posterior, probablemente el de 1562, que llevó ante Felipe II a Lucas García, Alonso Gómez, Antonio del Pedroso y Pablo de Galicia, pertenecientes respectivamente a las cabeceras, de Tepeticpac, Quiahuistlan, Ocotelulco y Tizatlan; obtuvieron diversas cédulas incluyendo la fechada el 25 de abril de 1563 declarando a Tlaxcala «muy noble y muy leal ciudad» ${ }^{42}$. Para 1584 se afirma que fueron a Castilla don Antonio de Guevara, don Pedro de Torres, don Diego Telles y don Zacarías, contando la marcha como la «quinta vez» ${ }^{43}$. Gibson ${ }^{44}$ afirma que Diego Muñoz Camargo acompañó a la expedición como intérprete. En 1585 se otorgó en Barcelona a Tlaxcala el título de «Muy Insigne» ${ }^{45}$, lo cual muy pudo ser fruto del viaje aludido. Varios de los protagonistas del mismo estaban de vuelta en Tlaxcala poco después, pues en 1589 consta que don Zacarías de Santiago era el gobernador, y don Pedro de Torres, alcalde; por su parte, Diego Telles fue alguacil mayor en $1590^{46}$. Quizá no volvieron todos, pues en 1590 el gobernador don $\mathrm{Za}$ carías de Santiago salió a recibir a los que llegaban de España a Atlancatepec ${ }^{47}$.

38 Mendoza, 1547: 87.

39 Gibson, 1967: 165.

40 Zapata, 1995: 144, 145.

41 Zapata, 1995: 168, 169.

42 Gibson, 1967: 166.

43 Zapata, 1995: 174-175.

44 Gibson, 1967: 167.

45 Zapata, 1995: 174, 175.

46 Zapata, 1995: 174, 175.

47 Zapata, 1995: 178, 179. 


\section{El VIRReinato Del Perú}

Pease $^{48}$ nos proporciona algunos ejemplos de kurakas que iban a España, como los de Jauja:

Los curacas de Jauja eran ricos, y los documentos publicados por Espinoza lo aseveran no sólo aclarando que Felipe Guacra Paúcar estuvo en España largo tiempo, sino que antes del viaje su padre había mandado construir la iglesia de San Jerónimo de Tunán, donde deseaba ser enterrado. Se requiere de mayor información acerca de los curacas de Jauja y de la forma como obtuvieron el dinero en efectivo para aquellos gastos, así como los derivados del largo proceso administrativo que se aprecia en los documentos publicados por Espinoza. Un siglo después, otro curaca de Lurin Guanca, Jerónimo Lorenzo Limaylla, viajaría por más largo tiempo a la península; como luego se verá, estuvo en España casi siete años, y en ese tiempo presentó numerosos memoriales ante la administración metropolitana ${ }^{49}$.

Parece ser que son asuntos de «negocios» los que retuvieron tanto tiempo a D. Jerónimo, y su presencia tiene dos vertientes que debemos estudiar: cómo queda su patrimonio en el Perú, quién lo administra y cómo recibe los fondos necesarios para mantenerse en España, por un lado, y sus actividades en la Península, que alguna huella habrán dejado en los Archivos, por otro.

En 1667 se hallaba Jerónimo Lorenzo Limaylla, viviendo en España ocupado en el seguimiento de un pleito sobre el curacazgo de Lurin Guanza, apelado ante el Consejo de Indias. Años después se hallaba todavía allí y había presentado largos memoriales y probanzas, algunos de los cuales se hallaban impresos; puede discutirse las fechas de su estadía, pero se conocen ahora los memoriales (veáse Apéndi(ce) $)^{50}$.

No era la primera vez que el kuraka iba a España. En 1662 había pedido ya autorización y parece que en 1647 había estado en la Península ${ }^{51}$.

Durante sus estancias en España, Limaylla presentó varios memoriales al rey en uno de los cuales se afirma que tenía un poder para actuar otorgado por los caciques del Perú 52 .

La lectura de dicho memorial ${ }^{53}$ nos ilustra sobre las pretensiones de nobleza de estos señores y la facilidad con que se dirigían al rey. Al presumir Don Jerónimo de tener poderes de los kurakas, parece que la petición no sería inspiración de un día, sino que vendría meditada de antiguo. La posibilidad de

48 Pease, 1992.

49 Pease, 1992: 157-158.

50 Pease, 1992: 163.

51 Pease, 1992: 164-165.

52 Pease, 1992: 165.

53 AGI, Sevilla, Indiferente General 640, en Pease, 1992: 173-178. 
que los señores indígenas se pongan de acuerdo y un representante suyo vaya a España a entenderse directamente con la Corona es muy interesante y debe ser investigada con más detenimiento.

En el propio expediente de Huancavélica se encuentran cartas de Joseph Sulcaguaman, del propio tiempo de la rebelión, quien también escribe a Bartolomé de Mendoza indicándole su intención de viajar a España (A.C.P.H., Expedientes coloniales, s.n., Cfr. Pease 1982a).

Los viajes de los curacas no eran novedad; se vio anteriormente que cien años antes don Felipe Guacra Paúcar, curaca de Jauja lo llevó a efecto. En 1646 viajó a la península don Carlos Chimo, curaca de Lambayeque, en 1662 lo hizo Antonio Collatopa, curaca cajamarquino, quien presentó un memorial impreso donde se denunciaban las molestias que recibían los pobladores andinos (Cfr. Vargas Ugarte 1949: 199). La cédula real de 6-VIII-1664 mencionó la estancia de Collatopa en España, al parecer acompañado del agsutino fray Juan de la Madre de Dios, y se hizo referencia a los memoriales de Juan de Padilla y a las consultas y juntas mandadas hacer por el rey con referencia al mismo ${ }^{54}$.

\section{La familia del Inca}

Una muestra de la riqueza que nos espera puede ser la siguiente cita en la que aparecen distintos personajes procedentes del Perú y algunas de las relaciones que establecieron entre ellos:

El 9 de octubre de 1619 se otorgó escritura de transacción entre los siguientes: Juan Melchor Carlos Inga, hijo de Melchor Carlos Inga, caballero de Santiago, difunto; Gaspar Rodriguez Cortés, curador de María Coya, monja novicia en el monasterios de las Bernardas de Vallecas; P. Francisco de Figueroa, S.J., en nombre de Juan Guauchuri y de su mujer D. ${ }^{a}$ Juana Yupanqui Inga, y Alonso Díaz de Guitián, en nombre de D. ${ }^{a}$ Melchora Clara Coya, monja en el Convento de Nuestra Señora de los Remedios del Cuzco, que en el siglo se llamaba Doña Leonor de Esquivel, de una parte, y de la otra, Cristóbal Pérez de Urízar, en nombre de Doña María de Silva, viuda de D. Melchor Carlos Inga.

Es materia de escritura lo siguiente: Melchor Carlos Inga, en su testamento extendido en Alcalá de Henares, el 2 de octubre de 1610, ante Juan de Quintarna, en una claúsula dejaba por herederos a su hijo, el referido Juan Melchor Carlos Inga, a Carlos Inga, difunto, a María Coya, a Melchora Clara Coya y a Juana Yupangui, no obstante que no eran legítimos, y en otra claúsula disponía que una vez pagadas las mandas consignadas en dicho testamento, fuese su heredero universal Felipe Carlos Inga, habido en su segunda mujer D. ${ }^{a}$ María de Silva, con la condición de que si éste falleciese en edad pupilar, antes de estar en aptitud de disponer de sus bienes, heredaran éstos los demás hijos del testador por iguales partes, salvo una renta de mil ducados. Como había muerto el citado Felipe Carlos, era llegado el caso de venir a suceder en sus bienes sus hermanos ilegítimos.

54 Pease, 1992: 165. 
Por otra parte, D. ${ }^{a}$ María de Silva había entablado instancia ante el Consejo de Indias, en su calidad de madre y heredera del repetido Felipe Carlos Inga, alegando ser sucesora en la parte proporcional de la renta anual de 1.500 ducados asignados a su difunto marido por Cédula de 18 de enero de 1606, ya que había invertido 2.000 ducados en la educación de dicho vástago suyo, desde el 4 de octubre de 1610 en que falleciera Don Melchor Carlos Inga, hasta el 23 de junio de 1611, en que muriera su tantas veces nombrado hijo. Salieron a oponerse los demás afectados, y el Consejo de Indias libró auto amparando la pretensión de estos últimos ${ }^{55}$.

Conocemos algunas noticias biográficas de don Melchor Carlos Inca gracias a Casado ${ }^{56}$. Había nacido en el Cuzco en 1574, hijo legítimo de don Carlos Inga Yupanqui y de doña María Amarilla de Esquivel, siendo su padrino el Virrey del Perú, don Francisco de Toledo. Era nieto de don Cristóbal Paullu, quien ejerció como Inca tras la rebelión de Manco Capac y hasta su muerte en 1549. Casó dos veces, una en 1599 con doña Leonor Arias Carrasco, natural del Cuzco, y otra con la mencionada doña María de Silva, natural de Madrid, aunque por el fallecimiento de nuestro personaje no llegó a efectuarse la ceremonia canónica ${ }^{57}$. Fue caballero de la Orden de Santiago desde 1606. Esta dignidad fue alcanzada también en 1627 por uno de sus hijos ilegítimos, Juan Melchor Carlos Inca, nacido en Cuzco en 1592, hijo de Francisca Quispe. Don Melchor Carlos había venido a España en cumplimiento de órdenes del rey, con una merced de 7.500 ducados de renta ${ }^{58}$. Glave ${ }^{59}$ afirma que se le había atribuido participación en un supuesto complot contra el rey y por ello había sido deportado a España «para tranquilidad del reino». En 1603 recibió un poder de los Incas de sangre real, junto a Garcilaso de la Vega el Inca y Alonso de Mesa, para realizar gestiones en la Corte $^{60}$. No olvidemos que el padre de don Melchor Carlos y Garcilaso habían sido condiscípulos en el Cuzco ${ }^{61}$ y estuvieron juntos en la fiesta de Corpus Christi en que se dio la bienvenida a Sayri Tupac ${ }^{62}$. Estableció su residencia en Trujillo, de donde era originaria su madre ${ }^{63}$ y la muerte le sorprendió en Alcalá de Henares en 1610. Mientras tanto vivió en Valladolid, con un «tren de vida poco honorable» ${ }^{64}$, que a decir de

55 Protocolo de Hernando de Recas, 1619, fol. S.n., Protocolo 3173; Lohmann, XXV (Madrid, 1960-61): 467-468.

56 Casado, 4 (Madrid, 1999): 43-49.

57 Casado, 4 (Madrid, 1999): 44.

58 Inca, 1976, II: 283.

59 Glave, 1998: 26.

60 Inca, 1976, II: 281. Iwasaki, XLVI/177 (Madrid, 2003): 59-74.

61 Miró, 1976: XXXI.

62 Lorandi, 1997: 79.

63 Vázquez de Espinosa, 1992, II: 787.

64 Bernand, 2006: 247. 
Lohmann ${ }^{65}$ «como correspondía a los peruleros, era manirroto y generoso»y que «la fama que había adquirido de libertino y desgarrado era similar a la que había aconsejado al Virrey Velasco a desterrarlo del Perú». Hace referencia a un episodio cuya fuente hemos podido localizar y que transcribimos por su interés para mostrar el papel en la corte de D. Melchor, el tenor de sus andanzas y lo que podríamos nosotros encontrar escrutando en documentación distinta a la que habitualmente utilizamos. Dada la rareza de la obra, reproducimos completo el párrafo:

Referiré, a este propósito de las buenas y honradas madres, una escritura auténtica y pública, colocada en los archivos de mi memoria, sin cosa que ofrezca duda, ni tachadura, sino una que la madre tiene en las quijadas.

Vino a esta ciudad una señora con dos hijas, doña Agustina de Valles, de 22 años, y doña Ana, de 17, y sin duda, de las más hermosas mozas que hay en la corte. Recibían de muchos que las servían, sin dar entrada a ninguno (puede ser que por encarecer la mercancía), hasta que, haciéndolas salir de la corte, fue necario [sic por necesario] a la de más edad, para encontrar favor, dársele a algunos, y para que la dejaran entrar, dar algunas entradas, todo por su justo precio.

Vencida esta fortaleza, comenzaron a acometer la otra, que se suponía estaba más entera y había más dificultad en la entrada. Intentáronlo en fin, por el postigo viejo de la madre, que vino a pleitesías y puso el negocio en almoneda. La mejor postura fue la de D. Melchor Carlos Inga, nieto del rey del Perú, que ofreció mil cruzados, la mitad luego de buena entrada de Pascua de Flores y la otra por San Juan, en la venida de la armada, sobre las cuales capitulaciones se hizo una escritura que leí, y el tenor y sustancia de ella es el siguiente:

En la ciudad de Valladolid, en los 25 de Marzo deste presente año de 1604, en las casas donde vive la señora doña Francisca de Valles, viuda de Diego Zamora Zurita, que Dios haya, estando presente el señor D. Melchior Carlos Inga, por él fué dicho en presencia de mi escribano, que por las muchas obligaciones que él tenía y adelante esperaba recibir de la señora doña Ana de Valles, hija doncella de la dicha señora doña Francisca, y en satisfacción de cierta promesa y concierto que entre ellos pasó, de que darán fee los testigos suso escrito y firmados, daba y confesaba deber a la dicha señora mil ducados de a once reales el ducado, de los quales se obliga a dar y entregar luego en joyas y buena moneda a la dicha señora quinientos dineros para poner su casa, y la otra mitad en llegando la armada del Perú; con declaración que las dichas señoras, por razón de las dichas obligaciones presentes y futuras, que los dichos testigos declararon, no podrán pedir más nada que los dichos mil ducados; y por ellas fué dicho que se daba por satisfechas y pagadas en la sobredicha manera, de todas las obligaciones futuras y pasadas, y a que ni con pretexto de engaño, ni fuerza, ni honra de deudos ni agüelos, ni por razón de dote o casamiento, ni otra manera, pedirán al dicho señor D. Melchior cosa alguna, antes se obligaba a no ser ingrata a esta donación ni agraviar al dicho señor hasta el tiempo de la cobranza de la dicha media paga, con pena de perderla; y así lo otorgaron, renunciando a la ley de non numerata pecunia y el Macedoniano y restitución de me-

65 Lohmann, XIX (Madrid, 1948-49): 365. 
nores, visto ser acto para que tiene perfecta edad y intervenir el consentimiento de la dicha señora su madre, mayor de edad, y a cuya cuenta está la dicha su hija. Fermaron: D. Melchior Carlos Inga.- D. ${ }^{\mathrm{a}}$ Francisca de Valles.- D. ${ }^{\mathrm{a}}$ Ana de Valles. Testigos: María Ortiz, su criada.- Ana de Oriza, huéspeda. - La comadre de Valdemoro, Juana Ruiz. Pasó ante mí, Jerónimo Pereira, escribano público por su magestad, etc.

El Don Melchor cobró las obligaciones por entero y dejó a deber la media paga, porque halló otra escritura que la niña había hecho anteriormente en Madrid, del mismo tenor, con lo cual se exime, por venderle moneda falsa y cercenada ${ }^{66}$.

Como hemos visto, su testamento dio origen a distintas controversias, hasta solucionarse con la escritura citada anteriormente, quedando como descendiente directo de los reyes incas del Perú D. Juan Melchor Carlos Inca, quien vivía con «harta pobreza» en la corte ${ }^{67}$. Lo de la pobreza debió solucionarse en algún momento, o simplemente es una muestra más de la ligereza con que se habla de los bienes:

En Santiago de Oropesa, capital de su Estado, vivió en unas casas que fueron construidas por el conquistador Feliciano de Silva, y que luego pertenecieron a don Melchor Carlos Inga, de cuya testamentaría las adquirió a su turno el Marqués, que abonó por el traspaso la suma, bastante considerable, de 50.000 pesos $^{68}$.

A este linaje afirmó pertenecer Pedro Bohorques para justificar su derecho a proclamarse Inca ${ }^{69}$.

La aparición de los Marqueses de Oropesa es otra muestra de las vinculaciones familiares que se mantenían tanto en el Perú como en España. Tras la rendición de Sayri Tupac, en aquel momento Inca de Vilcabamba (1558), recibió, entre otras recompensas, el valle del Yucay. Murió poco después dejando una hija que tras diversas vicisitudes casó hacia 1577 con Martín García Oñez de Loyola. Éste obtuvo una Real Cédula el 16 de septiembre de 1577 en la que en atención a sus servicios y a su boda, el rey le concedía 1.000 pesos de renta por su vida y la de un sucesor. Este estipendio comenzaría a pagarse cuando se embarcara junto con su esposa hacia la Península, lo que debía ocurrir en un plazo de tres años ${ }^{70}$. El viaje parece que no llegó a producirse. La pareja tuvo una hija, y D. Martín fue nombrado gobernador de Chile, lugar donde encontró la muerte.

El Virrey del Perú Luis de Velasco ordenó que la viuda e hija del Gobernador fueran conducidas a Lima, donde con efecto se establecieron, cuidando el propio vi-

\footnotetext{
66 Veiga, 1989: 197-198. Entrada correspondiente al 30 de junio.

67 Vázquez de Espinosa, 1992, II: 788.

68 Lohmann, XIX (Madrid, 1948-49): 383.

69 Lorandi, 1997: 81.

70 Lohmann, XIX (Madrid, 1948-49): 360.
} 
cesoberano de que en atención a los méritos del difunto se guardase a ambas mujeres el respeto debido. Disfrutaban a la sazón de una renta anual de diez a doce mil pesos, suma que el Virrey estimaba competente como futura dote de la menor. Por razones políticas, Velasco contemplaba las ventajas que provendrían de que tanto doña Beatriz Clara, como su primo segundo don Melchor Carlos Inga y Esquivel, ambos descendientes legítimos de Huayna Cápaj y el segundo titular de la dinastía incaica por línea de varonía, fuesen invitados a residir en Madrid adonde se le permutaría las rentas de que disfrutaban en el Perú ${ }^{71}$.

El matrimonio de la joven ñusta fue sonado, pues emparentó con la más alta nobleza castellana, generando una madeja de relaciones que abarcaba su patria ancestral y la nueva. Es importante seguir el entramado genealógico para comprender el alcance de la alianza matrimonial72. Aquí nos limitaremos a mencionar a las casas de Loyola y Borja, que establecen la primera conexión con la Compañía de Jesús, pero también aparecen los Enríquez de Almansa, marqueses de Alcañices, con mucha presencia en América en los más altos cargos, el condestable de Castilla, el duque de Albuquerque y el duque de Frías, entre otros, por no dejar atrás al Príncipe de Esquilache. Los sucesivos matrimonios fueron enredando cada vez más la madeja o tupiendo la red.

En definitiva, mucha gente yendo y viniendo, cambiando de tierra y de familia. Hay que destacar que entre las relaciones familiares de don Juan y doña Ana María, figuraron también el Duque de Lerma, el Duque de Uceda y el Conde-Duque de Olivares, por lo cual no debe extrañarnos que las peticiones de la pareja sobre la herencia del abuelo de la novia prosperaran, y les fuera concedido el Marquesado de Oropesa ${ }^{73}$. Y si contemplamos lo que cada uno llevó al matrimonio, la ñusta gana con gran ventaja ${ }^{74}$. Por cierto, que quien gestionó que se obligara a esta familia a salir del Perú fue su pariente el Príncipe de Esquilache, en 1634, siendo Virrey del Perú ${ }^{75}$. La alianza entre los Loyola, los Borja y los Incas fue objeto de una serie de cuadros existentes en distintos lugares del Perú, lo que nos muestra la importancia de la evolución de esta familia. Los lazos de familia vuelvan a aparecer en el siglo XVIII:

Uno de los recurrentes [al título de Santiago de Oropesa, vacantes tras la muerte sin descendencia de la 5. ${ }^{a}$ Marquesa en 1741] fue el Gentilhombre de Boca, con ejercicio, Juan de Bustamante Carlos Inga, oriundo del Cuzco y a la sazón residente en Madrid. Inició este su demanda en 1746, y el juicio continuó ventilándose hasta 1759. Fundaba su pretensión al Señorío vacante en que le correspondía por derecho

71 Lohmann, XIX (Madrid, 1948-49): 362-363.

72 Riva Agüero, 1931: XIX-XX.

73 Lohmann, XIX (Madrid, 1948-49): 365-372.

74 Lohmann, XIX (Madrid, 1948-49): 377-378.

75 Lohmann, XIX (Madrid, 1948-49): 433. 
de sangre, en razón de ser sexto nieto de don Cristóbal Paullu Topa, tío del Inga Sayri Túpaj, abuelo a su vez de la primera marquesa se Santiago de Oropesa ${ }^{76}$.

Bustamante no consiguió lo que se proponía, pero su constancia le valió el nombramiento de Gentilhombre de Boca, una asignación anual de 2.000 ducados y un pago único de subsidio de viaje de 4.000 ducados $^{77}$. Su estancia en España duró de 1725 a 1747.

Un personaje central en nuestro discurso es Garcilaso de la Vega el Inca. Nacido en el Perú de padre español y madre de la realeza inca, convivió en el Cuzco con otros mestizos como él y con Incas como D. Carlos, el hijo de Cristóbal Paullu, como hemos tenido ocasión de señalar. Allí tuvo ocasión de contemplar episodios como la entrada de Sayri Tupac en el Cuzco o la procesión del Corpus en la que el cañari Francisco Chillche aludió a un episodio de la conquista en la que él, en representación de los españoles había vencido al representante de los Incas. El tumulto fue considerable y a quien le tocó apagar los fuegos fue al corregidor, a la sazón el padre de nuestro personaje. Pero nos interesan más las andanzas por España, donde llegó en 1561, llamándose Gómez Suárez de Figueroa. Se estableció en Montilla, de donde era originaria la familia de su padre, pero pasó temporadas en la Corte, donde trató, por ejemplo, con Hernando Pizarro y su reciente esposa, su sobrina doña Francisca, la hija de Francisco Pizarro y doña Inés Yupanqui, quienes no solamente procedían del Perú, sino que estaban emparentados con nuestro cronista por la parte incaica. Una circunstancia interesante es que cambió su nombre por el de Garcilaso de la Vega el Inca. Como hemos visto, tuvo contactos a principios del siglo XVII con D. Melchor Carlos Inca, a quien encomendó la misión encargada, quizá porque en el lienzo remitido con la descendencia de los Incas, sólo aparecía la procedente de las líneas masculina ${ }^{78}$. Bernand pone en duda que Garcilaso no se enterara, en incluso que no tuviera contacto, con Ana María Coya, llegada en 1603, ya que esta pasó por Córdoba ${ }^{79}$. También supone el contacto, aunque menciona que Garcilaso no da noticias, Lohmann ${ }^{80}$.

D. ${ }^{a}$ Francisca Pizarro, hija del conquistador, también pasó a España, donde casó con su tío Hernando Pizarro. Sus aventuras en la corte, sus contactos con parientes como Garcilaso, y el destino del linaje han sido narrados por Rostworowski ${ }^{81}$.

\footnotetext{
76 Lohmann, XIX (Madrid, 1948-49): 407-408.

77 Cahill, 2006: 183.

78 Bernand, 2006: 248.

79 Bernand, 2006: 248-249.

80 Lohmann, XIX (Madrid, 1948-49): 365.

81 Rostworowski, 1989.
} 


\section{REFLEXIONES SOBRE LOS CASOS PRESENTADOS}

Como ya hemos mencionado, los tlaxcaltecas se movieron mucho, pero no debemos descartar que miembros de otros grupos indígenas se movieran también, por ejemplo, en los séquitos de virreyes y otros oficiales reales que circulaban por las distintas administraciones americanas. Quizá llegara de esa manera la «india mexicana de Aquellatepec» Ysabel, cuyo hijo participaba en el envío de coca a Potosís ${ }^{82}$. Un recorrido inverso, cuyos detalles desconocemos, llevó D. Francisco Benítez Ynga, quien fue gobernador de Tenochtitlan en 1659 y $1660^{83}$. En la contradicción a su elección se le acusó de ser «mestizo del Perú $\rangle^{84}$

Lo que hemos presentado nos permite ver cómo los indígenas, sobre todo los de clases altas, viajaban a España a realizar diversos negocios o a residir permanentemente. En ambos casos establecen contactos con conocidos o con parientes, pues el mestizaje permite tener familiares a ambos lados del Atlántico, con resultados que están pendientes de analizar. Pudieron crearse nuevas redes, o pudieron aprovechar las existentes, del tipo de las que aparecen en los trabajos de Altman ${ }^{85}$ o Pelegrí ${ }^{86}$. Esas redes no solamente podían articular los viajes, sino también garantizar la gestión de los bienes a uno y otro lado del Atlántico, y si en ellas participaban españoles — peninsulares e indianos-, mestizos e indígenas, no debemos olvidar que podría tratarse de parientes. Un ejemplo de ello es el conquistador Hernán Cortés, una de cuyas hijas es mestiza y está emparentada con el mestizo Juan de Andrade y con el indígena Diego Luis Moctezuma, por citar solamente un caso señalado.

Los motivos y circunstancias de los viajes de estos indígenas es un tema digno de atención, por sus repercusiones a ambos lados del Atlántico. En el caso de los principales, es necesario atender a la organización de sus asuntos en sus lugares de origen, pero cuando se quedan a vivir en España, hay que ver cómo se desarrollan los acontecimientos. En la corte, al menos para los de más alta alcurnia, primaba su linaje sobre su condición de indígena. Es éste un aspecto de la vida hispanoamericana que está pendiente de estudio y consideramos que lo presentado nos anima a pensar que dejó rastros en la documentación española, rastros que conviene seguir. Los nombres y fechas aquí reseñados pueden ser un punto de partida que nos guía por los archivos españoles y

82 Numhauser, 2005: 282.

83 Estrada, 2000: 187.

84 Estrada, 2000: 78.

85 Altman, 1992.

86 Pelegrí, 2004. 
americanos en busca de más detalles de estos viajes y de las extensas relaciones que implicaron.

NOTA: La investigación en que se enmarca este artículo ha sido realizada en el seno del Grupo de Investigación 941053 Expansión europea: exploraciones, colonizaciones y descolonizaciones que dirige el Dr. D. Mariano Cuesta Domingo.

\section{BIBLIOGRAFÍA}

Aguilar, Manuel, «The indio ladino as cultural mediator in the Colonial society», Estudios de Cultura Nahuatl, 33 (México, 2002): 149-184.

Albornoz, Rodrigo, «Carta autógrafa de... al emperador Carlos V, proponiendo mejores formas de gobierno y soluciones a distintos problemas en la Nueva España (México. AGI Patronato 184, ramo 2: f. 1-13)», Concepción Company (ed.), Documentos lingüísticos de la Nueva España. Altiplano Central, México D.F., Instituto de de Investigaciones Filológicas, UNAM, 1994: 23-47.

Altman, Ida, Emigrantes y sociedad. Extremadura y América en el siglo XVI, Madrid, Alianza, 1992.

Álvarez, Carlos, «El conde de Moctezuma en el Reino de Granada», El Reino de Granada y el Nuevo Mundo II, Granada, Diputación Provincial de Granada y Asociación Española de Americanistas, 1992: 105-116.

Audiencia de México, «Carta a la Emperatriz, de la..., diciendo que están tomando las residencias a los de la Audiencia anterior. De México a 30 de marzo de 1531», Epistolario de la Nueva España, II: 35-64.

Audiencia de México, «Carta a la Emperatriz. México, 10 de julio de 1532 (1532a)», Epistolario de la Nueva España, II: 183-193.

Audiencia de México, «Carta a la Emperatriz. México, 3 de noviembre de 1532 (1532b)», Epistolario de la Nueva España, II: 208-221.

Audiencia de México, «Carta al Rey. México, 31 de julio de 1541», Epistolario de la Nueva España, IV: 26-29.

Bautista, Juan, ¿Cómo te confundes? ¿Acaso no somos conquistados? Anales de Juan Bautista, ed. de Luis Reyes, México D.F., Biblioteca Lorenzo Boturini y CIESAS, 2001.

Bernand, Carmen, Un Inca platonicien. Garcilaso de la Vega 1539-1616, Paris, Ed. Fayard, 2006.

Cahill, David, «A liminal nobility: the Incas in the Middle Ground of Late Colonial Peru», David Cahill y Blanca Tovías (eds.), New World, First Nations. Native peo- 
ples of Mesoamerica and the Andes under Colonial Rule, Brighton, Sussex Academic Press, 2006: 169-195.

Casado, Manuel, «El Inca en la Alcalá de Henares de Cervantes. Melchor Carlos Inga y el Colegio-Convento de San Agustín el Real de la Universidad de Alcalá a comienzos del siglo XVII», Madrid, Revista de Historia y Arte, 4 (1999): 43-49.

Chimalpahin, Domingo de San Antón Muñón, Relaciones originales de Chalco Amaquemecan., México, FCE, 1965.

Chipman, Donald, Moctezuma's children. Aztec royalty under Spanish rule 1520-1700, Austin, University of Texas Press, 2005.

Cuevas, Mariano, Documentos inéditos del Siglo XVI para la Historia de México, México D.F., Ed. Porrúa, 1975.

Diccionario Porrúa de Historia, Biografía y Geografía de México, 2 vols., México D.F., Ed. Porrúa, 1976.

Emperatriz, «Respuesta de S.M. la... a la carta que recibió de la Audiencia de México. Medina del Campo, 14 de agosto de 1532», CODOIN, 2. ${ }^{a}$ serie, X: 106-135.

Estrada, María Isabel, San Juan Tenochtitlan y Santiago Tlatelolco: las dos comunidades indígenas de la ciudad de México. 1521-1700, Tesis de maestría, México D.F., Universidad Autónoma Metropolitana, 1999.

Gibson, Charles, Tlaxcala in the Sixteenth Century, Stanford, Stanford University Press, 1967.

Glave, Luis Miguel, De Rosa y espinas. Economía, sociedad y mentalidades andinas, siglo XVII, Lima, IEP y Fondo Central de Reserva del Perú, 1998.

Horcasitas, Fernando, «Los descendientes de Nezahualpilli: documentos del cacicazgo de Tetzcoco (1545-1855)», México D.F., Estudios de Historia Novohispana, 6 (1998): 145-185.

Inca, Garcilaso de la Vega el, Comentarios Reales, 2 vols., Sucre, Biblioteca Ayacucho, 1976.

Instrucciones, «... que dio la villa de Antequera a su procurador Diego de Porras de lo que tenía que pedir y negociar en la corte. Antequera, 23 de junio de 1531», Epistolario de la Nueva España, II: 89-103.

Iwasaki, Fernando, «Las panacas del Cuzco y la pintura incaica», Madrid, Revista de Indias, XLVI/177 (2003): 59-74.

Lockhart, James, La sociedad hispano-peruana 1532-1560, México D.F., Fondo de Cultura Económica, 1982.

Lohmann, Guillermo, «El Señorío de los Marqueses de Santiago de Oropesa en el Perú», Madrid, Anuario de Historia del Derecho Español, XIX (1948-49): 347-458.

Lohmann, Guillermo, «Documentos interesantes a la Historia del Perú en el Archivo de Protocolos de Madrid», Revista Histórica, XXV (Madrid, 1960-61): 450-477. 
López, Jerónimo, «Carta al rey de..., dando algunos informes de la visita del licenciado Tello de Sandoval, otros sobre encomiendas y de lo que convenía proveer para la seguridad y perpetuidad de la Nueva España, y pide se le cumplan las mercedes que tenía ofrecidas, México, 25 de febrero de 1545», Epistolario de la Nueva España, IV: 150-179.

Lorandi, Ana María, De quimeras, rebeliones y utopías. La gesta del Inca Pedro Bohorques, Lima, Pontificia Universidad Católica del Perú, 1997.

Martínez, Andrea, «Colonizaciones tlaxcaltecas», México D.F., Historia Mexicana, 170 (1993): 195-250.

Mendoza, Antonio de, «Fragmento de la visita hecha a..., 1547», Joaquín García Icazbalceta, Nueva Colección de Documentos para la Historia de México, México D.F., Ed. Porrúa, 1971, vol. II: 72-140.

Mira, Esteban, Indios y mestizos americanos en la España del siglo XVI, Madrid, Iberoamericana Vervuert, 2000.

Miró, Aurelio, «Prólogo», Inca, Garcilaso de la Vega el, Comentarios Reales, Sucre, Biblioteca Ayacucho, 2 vols., 1976: I-XLIV.

Moctezuma, Pedro, «Carta al Rey, 1567», Epistolario de la Nueva España, XVI: 81-82.

Muñoz Camargo, Diego, Relación de Tlaxcala, México D.F., UNAM, 1984.

Numhauser, Paulina, Mujeres indias y señores de la coca. Potosí y Cuzco en el siglo XVI, Madrid, Cátedra, 2005.

Pease, Franklin, Curacas, reciprocidad y riqueza, Lima, Pontificia Católica Universidad del Perú, 1992.

Pelegrí, Luis Vicente, El botín del Nuevo Mundo. Capitales indianos en Extremadura, Brenes, Muñoz Moya Editores Extremeños, 2004.

Riva Agüero, José de la, «Prólogo», Horacio Urteaga, El imperio Incaico: XI-XXI, Lima, Librería e Imprenta Gil, 1931.

Rojas, José Luis de, «De México a Granada: descendientes de Moctezuma en España», El Reino de Granada y el Nuevo Mundo, Granada, Diputación Provincial de Granada y Asociación Española de Americanistas, 1994, II: 117-134.

Rojas, José Luis de, «Por el humo se sabe dónde está el fuego. Evidencias de la complejidad social novohispana en el testamento de don Pedro Moctezuma», México D.F., Revista de Investigaciones Jurídicas, 25 (2000): 379-382.

Rojas, José Luis de, Cambiar para que yo no cambie. La nobleza indígena en la Nueva España, Buenos Aires, Ed. SB (en prensa).

Rostorowski, María, Doña Francisca Pizarro. Una ilustre mestiza 1534-1598, Lima, IEP, 1989. 
Taylor, William B., Ministros de lo sagrado, Zamora (Mich.), El Colegio de Michoacán, Secretaría de Gobernación, El Colegio de México, 1999.

Tezozomoc, Hernando Alvarado, Crónica Mexicayotl, México D.F., UNAM, 1975.

Vargas Ugarte, Rubén, Impresos peruanos publicados en el extranjero, Lima, Biblioteca Peruana, 1949.

Vargas Ugarte, Historia del Perú. Virreinato (siglo XVI), Buenos Aires, 1954.

Vázquez de Espinosa, Antonio, Compendio y descripción de las Indias Occidentales, Madrid, Historia 16, 1992.

Veiga, Tomé Pinheiro de, Fastiginia. Vida cotidiana en la Corte de Valladolid, Valladolid, Ed. Ámbito y Ayuntamiento de Valladolid, 1989.

Zapata, Juan Buenaventura, Historia cronológica de la Noble Ciudad de Tlaxcala, Tlaxcala, Universidad Autónoma de Tlaxcala y CIESAS, 1994.

Zumárraga, Fray Juan de, «Carta al Emperador (1532)», Mariano Cuevas, Documentos inéditos del siglo XVI para la Historia de México, México D.F., Ed. Porrúa, 1975: 17-46.

\section{ONE-WAY TICKETS AND ROUND TRIPS. NATIVE AND MIXED-BLOOD AMERICANS WHO VISITED SPAIN}

Starting from the pioneer study of Esteban Mira (2001), this paper looks for the travels of to Spain of American Indians, both in documents and chronicles, since the very moment of the Spanish Conquest, mainly those who travelled spontaneously or upon royal orders. The main aim is to show the necessity of deeply analyze these travels, their reasons and circunstances, and search for the eventual constitution of personal webs between the two shores of the Ocean.

KEY WORDS: American Indians, travels to Spain, personal webs. 